Proc. of the 15th Int. Workshop on Slow Positron Beam Techniques and Applications, Prague, September 2-6, 2019

\title{
Investigation of Optical Properties and Defects Structure of Rare Earth (Sm, Gd, Ho) Doped Zinc Oxide Thin Films Prepared by Pulsed Laser Deposition
}

\author{
M. Novotny ${ }^{a, *}$, P. Hruska ${ }^{a, b}$, P. Fitl ${ }^{a}$, E. Maresova ${ }^{a, c}$, S. Havlova $^{a, c}$, J. BuliR $^{a}$, \\ L. Fekete ${ }^{a}$, R. YAtskiv ${ }^{d}$, M. VRnata ${ }^{c}$, J. Cizek ${ }^{b}$, M.O. Liedke ${ }^{e}$ And J. LAnCok ${ }^{a}$ \\ ${ }^{a}$ Institute of Physics of the Czech Academy of Sciences, Na Slovance 2, CZ 18221 Praha 8, Czech Republic \\ ${ }^{b}$ Faculty of Mathematics and Physics, Charles University, V Holesovickach 2, CZ 18000 Praha 8, Czech Republic \\ ${ }^{c}$ University of Chemistry and Technology, Prague, Technicka 5, CZ 16628 Praha 6, Czech Republic \\ ${ }^{d}$ Institute of Photonics and Electronics of the Czech Academy of Sciences, \\ Chaberska 57, CZ 18251 Praha 8, Czech Republic \\ ${ }^{e}$ Helmholtz-Zentrum Dresden-Rossendorf, Institute of Radiation Physics, \\ Bautzner Landstr. 400, 01328 Dresden, Germany
}

\begin{abstract}
Rare earths $(\mathrm{RE}=\mathrm{Sm}, \mathrm{Gd}, \mathrm{Ho})$ doped $\mathrm{ZnO}$ thin films were grown by pulsed laser deposition in oxygen ambient at pressure of $10 \mathrm{~Pa}$ on fused silica and $\mathrm{Si}(100)$ substrates at room temperature. A good optical quality of the films was confirmed by transmittance measurement in the visible spectral region. Photoluminescence suggested $\mathrm{RE}^{3+}$ oxidation state as confirmed at $\mathrm{ZnO}: \mathrm{Sm}$, where local structure was inhomogeneous. ZnO:Sm film exhibited the highest electrical resistivity while $\mathrm{ZnO}$ :Ho the lowest. Nanocrystalline structure of the films was observed by atomic force microscopy and X-ray diffraction. Defects structure was examined by variable energy positron annihilation spectroscopy. All ZnO:RE films exhibited significantly higher values of the $S$ parameter as well as shorter positron diffusion lengths compared to $\mathrm{ZnO}$ monocrystal reference due to trapping of positrons at open volumes associated with grain boundaries. We observed the impact of the type of RE dopant on optical and electrotransport properties while the defect structure remained unchanged.
\end{abstract}

DOI: 10.12693/APhysPolA.137.215

PACS/topics: 81.15.Fg, 78.70.Bj, 78.40.Fy, 61.72.uj, 73.61.Ga, 78.66.Hf

\section{Introduction}

In past decades a lot of efforts have been put in fabrication of high-quality zinc oxide thin films [1]. Such films of low defect concentrations can serve as a part of several optoelectronics devices (waveguides, LEDs, solar cells, and sensors) $[1,2]$. The optical properties can be tuned and enhanced by doping $\mathrm{ZnO}$ with rare earth $\left(\mathrm{RE}^{+}\right)$elements usually up to 5 at.\% [3, 4]. Strong emission lines in $\mathrm{ZnO}$ :RE structures can be obtained in the visible and infrared spectral region [4-9].

Pulsed laser deposition (PLD) has been shown as a promising technique for the fabrication of thin films of complex structure. $\mathrm{ZnO}$ films prepared by PLD exhibit typically oxygen deficiency leading to an enhanced concentration of oxygen vacancies $[10,11]$. Deposition in an oxygen enriched atmosphere can eliminate this problem and eventually create $\mathrm{Zn}$ vacancies. Positron annihilation spectroscopy (PAS) has been successfully employed in defects studies of $\mathrm{ZnO}$ bulks $[12,13]$ and $\mathrm{ZnO}$ films grown by PLD $[11,14,15]$. PAS has not been utilized yet in defect studies related to rare earth dopants in $\mathrm{ZnO}$ films.

\footnotetext{
*corresponding author; e-mail: novotnym@fzu.cz
}

This paper deals with optical and electrotransport properties, and defect structure examined by PAS of rare earths doped $\mathrm{ZnO}$ thin films prepared by PLD.

\section{Experimental}

$\mathrm{ZnO}: \mathrm{RE}(\mathrm{RE}=\mathrm{Sm}, \mathrm{Gd}, \mathrm{Ho})$ thin films were grown by PLD (Nd:YAG, $\lambda=266 \mathrm{~nm}, \tau=4 \mathrm{~ns}$, repetition rate $=10 \mathrm{~Hz}$ ) from $\mathrm{ZnO}: \mathrm{Sm}_{2} \mathrm{O}_{3}, \mathrm{ZnO}: \mathrm{Gd}_{2} \mathrm{O}_{3}$ and $\mathrm{ZnO}: \mathrm{Ho}_{2} \mathrm{O}_{3}$ targets (RE content was 1 at.\%) in oxygen ambient at pressure of $10 \mathrm{~Pa}$ at room temperature. A constant number of shots of 12,000 and laser fluence of $2 \mathrm{~J} / \mathrm{cm}^{2}$ were set for each sample deposition. The films were deposited on fused silica (FS) and $\operatorname{Si}(100)$ substrates. The distance between the target and the substrate was kept at $45 \mathrm{~mm}$.

The crystal structure and morphology of the films were characterized by X-ray diffraction (XRD, X'Pert, Co $K_{\alpha}$ radiation, $\lambda=1.789 \AA$ ) and atomic force microscopy (AFM). The optical properties were analyzed by UVVIS-NIR spectrophotometry, spectral ellipsometry (SE) (J.A.Woolam M-2000 ellipsometer) and photoluminescence (PL) ( $\mathrm{He}-\mathrm{Cd}$ excitation laser, $\lambda=325 \mathrm{~nm}$ ). The electrotransport properties of samples deposited on FS substrate were analyzed by the van der Pauw method. Gold contacts were pre-sputtered on the FS substrates. 
Parameters of $\mathrm{ZnO}: \mathrm{RE}$ films.

TABLE I

\begin{tabular}{c|c|c|c|c|c|c|c|c|c|c}
\hline \hline $\begin{array}{c}\text { ZnO:RE } \\
\text { sample }\end{array}$ & $\begin{array}{c}\text { Ionic } \\
\text { radius RE } \\
\text { Ref. [18] }) \\
{[\mathrm{pm}]}\end{array}$ & $\begin{array}{c}\text { Thickness } \\
{[\mathrm{nm}]}\end{array}$ & $\begin{array}{c}\text { Resistivity } \\
\rho\left[10^{4} \Omega \mathrm{cm}\right]\end{array}$ & $\begin{array}{c}\text { Band } \\
\text { gap [eV] }]\end{array}$ & $\begin{array}{c}\text { Positron } \\
\text { diffusion } \\
\text { length } \\
L_{+}[\mathrm{nm}]\end{array}$ & $\begin{array}{c}S \\
\text { param. }\end{array}$ & $\begin{array}{c}W \\
\text { param. }\end{array}$ & $\begin{array}{c}\text { Mean } \\
\text { crystallite } \\
\text { size [nm] }\end{array}$ & $\begin{array}{c}\text { Microstrain } \\
{[\%]}\end{array}$ & $\begin{array}{c}\text { Roughness } \\
\text { RMS [nm] }\end{array}$ \\
\hline ZnO:Sm & 95.8 & 195 & 4.26 & 3.32 & $5.9(4)$ & $0.5318(2)$ & $0.0937(2)$ & 40 & 0.098 & 8.1 \\
ZnO:Gd & 93.8 & 194 & 3.44 & 3.26 & $7.3(1)$ & $0.5294(2)$ & $0.0948(1)$ & 50 & 0.129 & 14.1 \\
ZnO:Ho & 90.1 & 213 & 0.0446 & 3.32 & $7.0(2)$ & $0.5306(2)$ & $0.0943(2)$ & 40 & 0.013 & 5.7
\end{tabular}

Variable energy positron annihilation spectroscopy (VEPAS) measurements were performed using a magnetically guided variable energy positron beam SPONSOR in HZDR with positron energies from $30 \mathrm{eV}$ to $30 \mathrm{keV} \mathrm{[16].}$ For each positron energy, the Doppler broadening of the annihilation profile was evaluated using the $S$ and the $W$ parameters. The dependence of the $S$ parameter on positron energy was analyzed using the VEPFIT code [17].

\section{Results and discussion}

The parameters of deposited $\mathrm{ZnO}$ :RE films are summarized in Table I. Let us discuss the results of particular analyses and related films properties.

\subsection{Optical properties}

Optical transmission UV-VIS spectra of ZnO:RE films deposited on FS substrate are shown in Fig. 1. The spectra revealed a good optical quality of $\mathrm{ZnO}$ material since the average transmittance exceeded $80 \%$ in the visible region. Tauc's plot method was used to estimate $E_{g}$ from a linear extrapolation of the dependence of $(h v \alpha)^{2}$ on the photon energy $h v$ ( $\alpha$ is absorption coefficient). We derived $E_{g}=3.32 \mathrm{eV}$ for $\mathrm{ZnO}: \mathrm{Sm}$, Ho and $E_{g}=3.26 \mathrm{eV}$ for $\mathrm{ZnO}$ :Gd film. The obtained $E_{g}$ values are in agreement with $\mathrm{ZnO}: \mathrm{Eu}$ film deposited by PLD [8].

The optical constants of $\mathrm{ZnO}: \mathrm{RE}$ films deposited on $\mathrm{Si}$ substrate extracted from spectral ellipsometry measurement are depicted in Fig. 2. The ellipsometry data were fitted using a multilayer model consisting of Si substrate, native silicon oxide, $\mathrm{ZnO}: \mathrm{RE}$, and effective medium approximation (EMA) roughness. ZnO:RE layer was modeled using the Cody-Lorentz and two Gaussian oscillators [19]. The optical constants did not differ compared to undoped $\mathrm{ZnO}[20]$.

Photoluminescence emission spectra of $\mathrm{ZnO}$ :RE films are shown in Fig. 3. Spectra exhibited typical features of PLD-grown $\mathrm{ZnO}$ where a dominating broad deep level emission (DLE) green-yellow band centered around $570 \mathrm{~nm}$ and near band edge (NBE) $\mathrm{ZnO}$ emission located at $382 \mathrm{~nm}$ are present. The defect-related luminescence is due to radiative transitions between deep acceptor ( $\mathrm{Zn}$ vacancy $\mathrm{V}_{\mathrm{Zn}}$ ) and shallow donors $\left(\mathrm{O}\right.$ vacancy $\mathrm{V}_{\mathrm{O}}$ and $\mathrm{Zn}$ interstitial $\mathrm{Zn}_{i}$ ) [13]. NBE originated from the free exciton recombination and its longitudinal-optical phonon replica [21]. In case of $\mathrm{ZnO}: \mathrm{Sm}$ the sharp emission lines

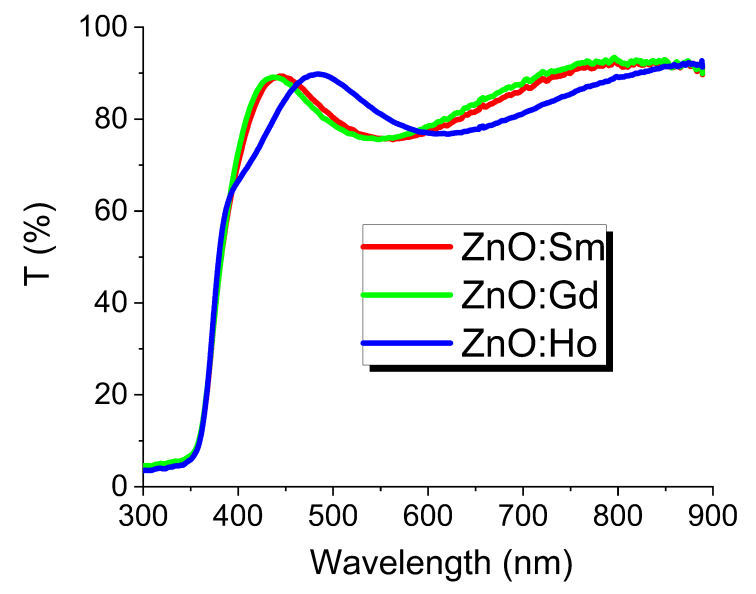

Fig. 1. Optical transmission of $\mathrm{ZnO}: \mathrm{RE}$ films.

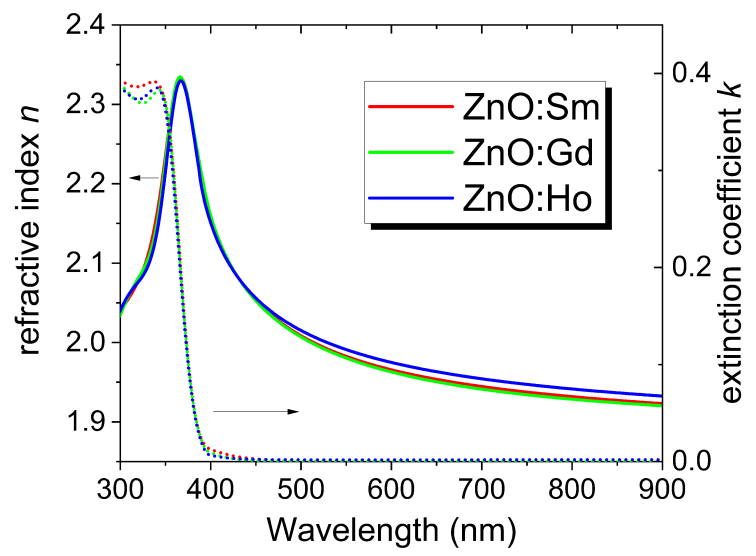

Fig. 2. Optical constants of $\mathrm{ZnO}$ :RE films.

superimposed on DLE band positioned at 567, 607, and $658 \mathrm{~nm}$ appeared. The lines can be attributed to ${ }^{4} G_{5 / 2}$ ${ }^{6} H_{J} \quad(J=5 / 2,7 / 2,9 / 2)$ intra-4f transition in $\mathrm{Sm}^{3+}$ ions. The appearance of several lines from the ${ }^{4} G_{5 / 2}{ }^{6} H_{J}$ transitions suggested the local structure around $\mathrm{Sm}^{3+}$ may be inhomogeneous [22]. The energy transfer from $\mathrm{ZnO}$ to $\mathrm{Sm}^{3+}$ had to take place since $\mathrm{Sm}^{3+}$ emission was stimulated by indirect excitation. The $I_{\mathrm{NBE}} / I_{\mathrm{DLE}}$ ratio of NBE and DLE bands, usually related to the structural imperfection including stoichiometry of the epitaxial $\mathrm{ZnO}$ layers, was the highest for $\mathrm{ZnO}: \mathrm{Sm}$ film $\left(I_{\mathrm{NBE}} / I_{\mathrm{DLE}}=0.155\right)$ while half of that value was obtained for $\mathrm{ZnO}: \mathrm{Gd}$, $\mathrm{ZnO}: \mathrm{Ho}$ films. 


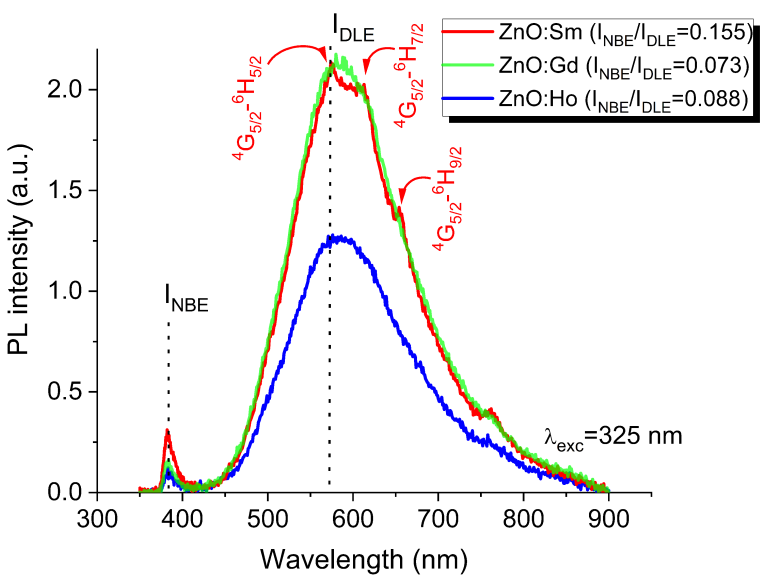

Fig. 3. Photoluminescence emission spectra of ZnO:RE films.

In case of $\mathrm{ZnO}$ : Gd we did not observe any strong emissions reported around 397, 432, 483, and $514 \mathrm{~nm}$ that were supposed to be induced by the impurity levels of $\mathrm{Gd}$ introduced into the band gap of the $\mathrm{ZnO}$ nanocrystals [4].

\subsection{Electrotransport properties}

The ZnO:Ho sample exhibited substantial lower electrical resistivity $\rho=4.46 \times 10^{2} \Omega \mathrm{cm}$ compared to $\mathrm{ZnO}: \mathrm{Gd}$ and $\mathrm{ZnO}:$ Sm where $\rho=4.46 \times 10^{4} \Omega \mathrm{cm}$ and $\rho=3.44 \times 10^{4} \Omega \mathrm{cm}$ were measured, respectively. The low $\rho$ might be related to lowest microstrain and roughness of $\mathrm{ZnO}$ :Ho sample that lead to lower electron scattering. Generally, higher values of $\rho$ are rather characteristic for high quality undoped ZnO prepared by PLD [23, 24], where it seems that $\mathrm{Sm}$ and Gd dopant level of 1 at.\% does not significantly contribute to PLD-grown $\mathrm{ZnO}$ electrical conductivity.

\subsection{Positron annihilation results}

Figure 4 shows dependence of the $S$ parameter of each $\mathrm{ZnO}: \mathrm{RE}$ film deposited on Si substrate on energy of incident positrons $(S(E)$ curve). At low positron energies $(<0.5 \mathrm{keV})$ virtually all positrons annihilated at the $\mathrm{ZnO}: \mathrm{RE}$ surface. Higher values of the $S$ parameter for $\mathrm{ZnO}: \mathrm{Sm}$ and $\mathrm{ZnO}$ :Gd films correlated with higher surface roughness determined by AFM (Table I). With increasing energy, the fraction of positrons diffusing from $\mathrm{ZnO}: \mathrm{RE}$ layer back to the surface gradually decreases as reflected by the decrease of the $S$ parameter. In the energy range from $2 \mathrm{keV}$ to $5 \mathrm{keV}$ almost all positrons annihilated in $\mathrm{ZnO}: \mathrm{RE}$ film and the $S$ parameter reaches a plateau. One can see in Fig. 4 that the plateau value is substantially higher than the reference value of hydrothermally grown $\mathrm{ZnO}$ monocrystal. At higher energies $(>5 \mathrm{keV})$ positrons start to penetrate to the Si substrate and the $S$ parameter increases and eventually at energies above $25 \mathrm{keV}$ reaches constant value close to the $\mathrm{Si}$ reference as it is depicted in Fig. 4.

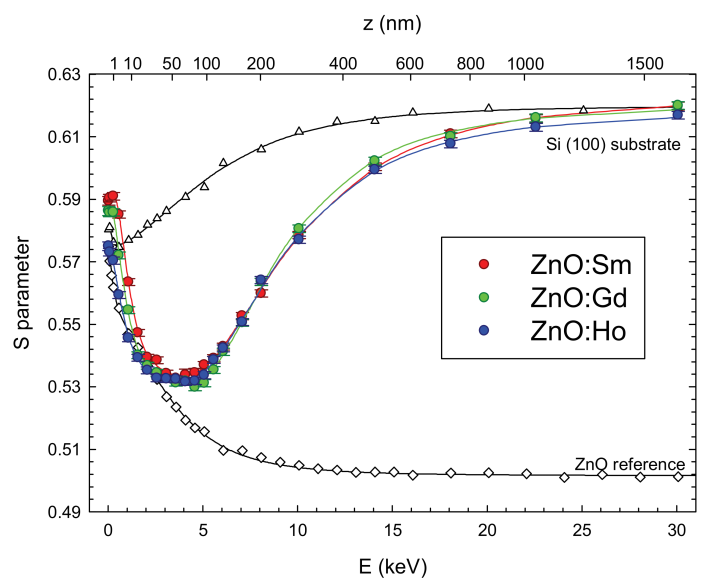

Fig. 4. $S(E)$ curves of $\mathrm{ZnO}$ :RE films. Solid lines correspond to result of two-layer VEPFIT model. Reference data for zinc oxide monocrystal and Si substrate are included.

Each $S(E)$ curve was fitted using the two-layer VEPFIT model ( $\mathrm{ZnO}$ layer and Si substrate).

ZnO:RE films are characterized by their $S$ and $W$ parameter and positron diffusion length $L_{+}$, which are listed in Table I. In general, thin films prepared by PLD might contain 2 types of defects: (A) vacancy-like openvolume defects associated with grain boundaries or misfit dislocations; (B) intra-granular defects, e.g., Zn and $\mathrm{O}$ vacancies. Type A defects characterize the film microstructure, while type B has a strong impact on electrical and optical properties. Considering nanocrystalline character of $\mathrm{ZnO}: \mathrm{RE}$ films dominating type of defects are supposed to be open volumes associated with the grain boundaries. $L_{+}$correlates well with the mean crystallite size determined from XRD.

Since the deposition conditions were kept constant for all $\mathrm{ZnO}: \mathrm{RE}$ films we might expect formation of the same amount of oxygen and zinc vacancies and examine the sole role of RE dopant. For positron annihilations inside the grains, the $S$ parameter should provide better insight into the dependence on dopant type. $\mathrm{RE}^{3+}$ are suggested to substitute $\mathrm{Zn}^{2+}$ sites [4], which may lead to local tensile lattice strain due to the smaller ionic radius of $\mathrm{Zn}^{2+}$ of $74 \mathrm{pm}$ [18]. Despite different ionic radii of $\mathrm{RE}^{3+}$ we observed no significant difference in $S$ parameter. Therefore, from this point of view (defects sensitive to this technique) we can conclude that the defect structure inside the grains is similar for all types of RE. Note that for the $W$ parameter, which is more suitable for resolving different RE types from each other, we did not observe any significant difference either.

\section{Conclusion}

Rare earths (Sm, Gd, Ho) doped ZnO nanocrystalline thin films were grown by PLD at room temperature. The $\mathrm{ZnO}: \mathrm{RE}$ films exhibited a good optical quality in the 
visible spectral region with optical constants similar to undoped $\mathrm{ZnO}$. Photoluminescence spectra of samples revealed typical features of PLD $\mathrm{ZnO}$ films — broad deep level emission green-yellow band centered around $570 \mathrm{~nm}$ and near band edge $\mathrm{ZnO}$ emission located at $382 \mathrm{~nm}$. The intensity ratio of these bands suggested the best quality of $\mathrm{ZnO}: \mathrm{Sm}$ film where also characteristic emission lines of intra-4f transition of $\mathrm{Sm}^{3+}$ ions induced by indirect excitation appeared in the spectra. The spectra indicated the inhomogeneous local structure. The lowest electrical resistivity of $4.46 \times 10^{2} \Omega \mathrm{cm}$ together with the lowest microstrain of $0.013 \%$ and roughness of $5.7 \mathrm{~nm}$ was obtained at $\mathrm{ZnO}: \mathrm{Ho}$ film.

ZnO:RE thin films contained two types of defects: (A) inter-granular structural defects (grain boundaries); (B) intra-granular defects with a strong impact on electrical and optical properties. The measurement of the $S$ parameter did not reveal any substantial dependence on the type of dopant.

\section{Acknowledgments}

We would like to express sincere thanks for support to Czech Science Foundation, project GA18-17834S. Research of R. Yatskiv and M. Vrnata was supported by the project GA19-02804S, Ministry of Education, Youth, and Sports, Czechia (projects LO1409 and LM2015088), and the Operational Program Research, Development, and Education financed by the European Structural and Investment Funds and the Czech Ministry of Education, Youth, and Sports (Project No. SAFMAT CZ.02.1.01/0.0/0.0/16 013/0001406).

\section{References}

[1] U. Özgür, Y.I. Alivov, C. Liu, A. Teke, M.A. Reshchikov, S. Doğan, V. Avrutin, S.J. Cho, H. Morkoç, J. Appl. Phys. 98, 041301 (2005).

[2] F. Rahman, Opt. Eng. 58, 1 (2019).

[3] L. Chen, J. Zhang, X. Zhang, F. Liu, X. Wang, Opt. Express 16, 11795 (2008).

[4] D. Daksh, Y.K. Agrawal, Rev. Nanosci. Nanotechnol. 5, 1 (2016).

[5] A. Ziani, A. Tempez, C. Frilay, C. Davesnne, C. Labbe, P. Marie, S. Legendre, X. Portier, Phys. Status Solidi C 11, 1497 (2014).
[6] W.M. Jadwisienczak, H.J. Lozykowski, A. Xu, B. Patel, J. Electron. Mater. 31, 776 (2002).

[7] S. Bachir, K. Azuma, J. Kossanyi, P. Valat, J.C. Ronfard-Haret, J. Lumin. 75, 35 (1997).

[8] M. Novotny, M. Vondracek, E. Maresova, et al., Appl. Surf. Sci. 476, 271 (2019).

[9] M. Novotny, E. Maresova, P. Fitl, et al., Appl. Phys. A 122, (2016).

[10] S. Choopun, R.D. Vispute, W. Noch, A. Balsamo, R.P. Sharma, T. Venkatesan, A. Iliadis, D.C. Look, Appl. Phys. Lett. 75, 3947 (1999).

[11] M. Novotny, J. Cizek, R. Kuzel, J. Bulir, J. Lancok, J. Connolly, E. McCarthy, S. Krishnamurthy, J.P. Mosnier, W. Anwand, G. Brauer, J. Phys. D Appl. Phys. 45, (2012).

[12] F. Tuomisto, I. Makkonen, Rev. Mod. Phys. 85, 1583 (2013).

[13] J. Cizek, J. Valenta, P. Hruska, O. Melikhova, I. Prochazka, M. Novotny, J. Bulir, Appl. Phys. Lett. 106, (2015).

[14] O. Melikhova, J. Cizek, I. Prochazka, et al., J. Phys. Conf. Ser. 443, 012018 (2013).

[15] M. Vlcek, J. Cizek, I. Prochazka, M. Novotny, J. Bulir, J. Lancok, W. Anwand, G. Brauer, J.P. Mosnier, J. Phys. Conf. Ser. 505, 012021 (2014).

[16] W. Anwand, G. Brauer, M. Butterling, H.R. Kissener, A. Wagner, Def. Diff. Forum 331, 25 (2012).

[17] A. van Veen, H. Schut, M. Clement, J.M.M. de Nijs, A. Kruseman, M.R. Ijpma, Appl. Surf. Sci. 85, 216 (1995).

[18] R. Shannon, Acta Crystallogr. A 32, 751 (1976).

[19] CompleteEASE, Data Analysis Manual Version 4.63, Woollam, Lincoln (NE) 2011.

[20] Y.C. Liu, J.H. Hsieh, S.K. Tung, Thin Solid Films 510, 32 (2006).

[21] C. Chen, H. He, Y. Lu, K. Wu, Z. Ye, ACS Appl. Mater. Interfaces5, 6354 (2013).

[22] T. Tsuji, Y. Terai, M.H.B. Kamarudin, M. Kawabata, Y. Fujiwara, J. Non-Cryst. Solids 358, 2443 (2012).

[23] J.N. Zeng, J.K. Low, Z.M. Ren, T. Liew, Y.F. Lu, Appl. Surf. Sci. 197, 362 (2002).

[24] S.P. Heluani, G. Braunstein, M. Villafuerte, G. Simonelli, S. Duhalde, Thin Solid Films 515, 2379 (2006). 